\title{
Adding Saxagliptin to Metformin Extended Release (XR) or Uptitration of Metformin XR: Efficacy on Daily Glucose Measures
}

Joel M. Neutel $\cdot$ Cathy Zhao $\cdot$ Chetan S. Karyekar

To view enhanced content go to www.diabetestherapy-open.com

Received: March 1, 2013 / Published online: July 24, 2013

(C) The Author(s) 2013. This article is published with open access at Springerlink.com

\section{ABSTRACT}

Introduction: Saxagliptin added to metformin extended release (XR) and uptitrated metformin $\mathrm{XR}$ were evaluated for their impact on daily glucose measurements and their tolerability in patients with type 2 diabetes mellitus (T2DM) inadequately controlled with metformin monotherapy.

Methods: Patients aged 18-78 years on metformin $850-1,500 \mathrm{mg}$ with glycated

ClinicalTrials.gov \#NCT00918138.

J. M. Neutel ( $\square)$

Orange County Research Center, 14351 Myford Rd, Suite B, Tustin, CA 93780, USA

e-mail: jmneutel@aol.com

C. Zhao

Bristol-Myers Squibb, Princeton, NJ, USA

C. S. Karyekar

Bristol-Myers Squibb, Global Clinical Research, Route 206 \& Province Line Rd, Lawrenceville, NJ 08543, USA

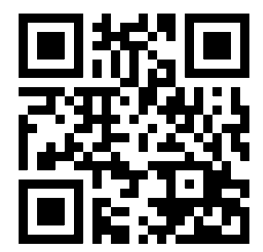

Enhanced content for this article is available on the journal web site: www.diabetestherapy-open.com hemoglobin $\left(\mathrm{HbA}_{1 \mathrm{c}}\right) \quad 7.5-11.5 \%$ at screening were eligible for this double-blind, activecontrolled study. Patients were stabilized on metformin XR 1,500 mg before randomization. Patients with $\mathrm{HbA}_{1 \mathrm{c}} 7-11 \%$ and fasting plasma glucose $(\mathrm{FPG}) \geq 126 \mathrm{mg} / \mathrm{dL}$ after a 4 - 8-week lead-in period were randomly assigned to saxagliptin $5 \mathrm{mg}+$ metformin XR 1,500 mg or metformin XR $500 \mathrm{mg}+$ metformin $\mathrm{XR}$ $1,500 \mathrm{mg}$ (uptitrated metformin XR). The primary end point was change from baseline to week 4 in 24-h mean weighted glucose (MWG). Secondary end points were changes from baseline to week 4 in 2-h postprandial glucose (PPG) and FPG.

Results: At week 4, the adjusted mean \pm SE change from baseline in 24-h MWG was $-19.0 \pm 5.7 \mathrm{mg} / \mathrm{dL}(95 \% \mathrm{CI}-30.3$ to -7.6$)$ for saxagliptin + metformin $\mathrm{XR}$ and $-8.2 \pm 6.0$ $\mathrm{mg} / \mathrm{dL}$ (95\% CI -20.0 to 3.7) for uptitrated metformin XR. Mean changes from baseline in 2-h PPG and FPG were numerically greater with saxagliptin + metformin $\mathrm{XR}$ versus uptitrated metformin XR. The incidence of adverse events was lower with saxagliptin + metformin XR (17.4\%) versus uptitrated metformin XR (31.9\%) mainly due to differences in 
gastrointestinal adverse event incidence (2.2\% vs $10.6 \%$, respectively). There were no reports of confirmed hypoglycemia in either group.

Conclusion: In this 4-week study in patients with T2DM inadequately controlled with metformin monotherapy, saxagliptin added to metformin XR demonstrated a trend for improvement in measures of daily glycemic control, with fewer gastrointestinal adverse events, compared with uptitrated metformin.

Keywords: Efficacy; Glycemic control; Metformin; Saxagliptin; Tolerability; Type 2 diabetes mellitus

\section{INTRODUCTION}

In patients with type 2 diabetes mellitus (T2DM), long-term control of blood glucose levels is necessary to help prevent the development of microvascular and macrovascular complications. Current guidelines from the American Diabetes Association/European Association for the Study of Diabetes (ADA/EASD) recommend that glycated hemoglobin $\left(\mathrm{HbA}_{1 \mathrm{c}}\right)$ be maintained at $<7.0 \%$ in most patients but be compatible with the patient's preferences, needs, and values, in line with the goal of providing patient-centered care [1]. Guidelines from the American Association of Clinical Endocrinologists/American College of Endocrinology (AACE/ACE) recommend a stringent $\mathrm{HbA}_{1 \mathrm{c}}$ target of $6.5 \%$ [2]. $\mathrm{HbA}_{1 \mathrm{c}}$ is influenced by increases in daily measures of glucose levels including fasting plasma glucose (FPG) and postprandial glucose (PPG), which are discrete values for measures of daily glucose levels. In addition, rapid daily fluctuations in glucose levels have been implicated as particularly important in contributing to diabetes-related complications [3]. Because average daily glucose measurements are strongly correlated with $\mathrm{HbA}_{1 \mathrm{c}}$ [4] and are important parameters for physicians to make therapeutic decisions, and because patients understand FPG and PPG better than $\mathrm{HbA}_{1 \mathrm{c}}$ [5], estimation of mean daily glucose parameters is critical. Twenty-four hour mean weighted glucose (MWG) can be used to provide an indication of the mean glucose exposure of the body over an entire day [6].

The ADA/EASD position statement recommends combination therapy when $\mathrm{HbA}_{1 \mathrm{c}}$ goals are not achieved or maintained during approximately 3 months with monotherapy [1]. However, uptitration of monotherapy is often practiced rather than addition of another agent [7, 8], which is delayed by an average 27-35 months [7]. The ADA/EASD and AACE/ACE recommend metformin as first-line drug therapy for T2DM $[1,2]$. Metformin is a biguanide that helps maintain glycemic control by suppressing glucose production by the liver [1]. Gastrointestinal disturbances (diarrhea, nausea, and vomiting) are the most common adverse events reported with metformin monotherapy, although the incidence is lower with metformin extended release (XR) versus metformin immediate release (IR) $[9,10]$.

Because T2DM is a progressive disease associated with worsening hyperglycemia, intensification of treatment over time through combination therapy typically becomes necessary for most patients to maintain glycemic goals $[1,11]$. After metformin is used, various strategies to achieve glycemic control can be applied. Antidiabetic medications with complementary mechanisms of action and differing safety and tolerability profiles can help improve glycemic outcomes with greater tolerability compared with 
uptitration of a single antihyperglycemic agent to the maximum dose $[1,12,13]$.

Saxagliptin is a dipeptidyl peptidase- 4 (DPP-4) inhibitor with a mechanism of action complementary to that of metformin. The DPP4 enzyme is involved in the degradation of the incretin hormones glucagon-like peptide 1 (GLP-1) and glucose-dependent insulinotropic peptide (GIP), both of which augment release of insulin from the pancreas in a glucosedependent manner; GLP-1 also decreases pancreatic glucagon secretion. By inhibiting DPP-4 degradation of GLP-1 and GIP, saxagliptin increases insulin secretion and suppresses glucagon release, complementary effects for controlling hyperglycemia [1, 14, 15]. DPP-4 inhibitors may also aid in beta-cell preservation, as suggested by preclinical evidence of inhibition of beta-cell apoptosis and necrosis and stimulation of beta-cell proliferation [16]. Saxagliptin is generally well tolerated for the treatment of T2DM [17]. The most commonly reported adverse events with saxagliptin are upper respiratory tract infection, urinary tract infection, and headache [18]. Saxagliptin is weight neutral and is not associated with hypoglycemia when used as monotherapy [17]; dose-adjustment from the approved 5-mg dose is not required in patients with hepatic impairment, but dose-reduction is required in patients with moderate to severe renal impairment and when coadministered with strong inhibitors and inducers of cytochrome P450 3A4 and 3A5 isoforms [17]. Postmarketing reports of pancreatitis have been reported with DPP-4 inhibitors, including saxagliptin $[17,18]$.

Saxagliptin has been shown to be efficacious and generally well tolerated as add-on therapy in patients with T2DM inadequately controlled with metformin monotherapy $[19,20]$ so it was theorized that addition of saxagliptin in patients inadequately controlled with metformin alone may improve efficacy and tolerability compared with uptitration of metformin. A previous study reported significant improvements in $\mathrm{HbA}_{1 \mathrm{c}}$ with the addition of saxagliptin to metformin $\mathrm{XR}$ versus uptitration of metformin XR over 18 weeks [12]. Here, findings are presented from a 4-week study in which the clinical effects, including impact on measures of daily glucose control, of adding saxagliptin $5 \mathrm{mg}$ to metformin XR 1,500 mg were compared with those of uptitrating metformin XR to the maximum daily dosage of 2,000 $\mathrm{mg}$ in patients with T2DM whose glucose levels were not adequately controlled with metformin monotherapy.

\section{MATERIALS AND METHODS}

The study protocol for this international, randomized, double-blind, phase $3 \mathrm{~b}$ trial was approved by the institutional review board and independent ethics committee at each site, and the study was conducted in accordance with Good Clinical Practice, as defined by the International Conference on Harmonisation. All procedures followed were in accordance with the ethical standards of the responsible committee on human experimentation (institutional and national) and with the Helsinki Declaration of 1975, as revised in 2000. Informed consent was obtained from all patients before being included in the study.

Men and women aged 18-78 years with T2DM were eligible for the study if they had been taking a stable daily dose of metformin IR or $\mathrm{XR} \geq 850$ and $\leq 1,500 \mathrm{mg}$ as monotherapy for $\geq 8$ weeks prescreening but had inadequate glycemic control, defined as $\mathrm{HbA}_{1 \mathrm{c}} \mathbf{7 . 5 - 1 1 . 5 \%}$ at screening. At screening, all previous metformin regimens were converted to metformin XR such that all patients were 
taking metformin XR 1,500 mg once daily. Patients also had to meet the following inclusion criteria during the screening period: $\mathrm{HbA}_{1 \mathrm{c}} 7-11.5 \%$ at 4 weeks before randomization, $\mathrm{HbA}_{1 \mathrm{c}} 7-11 \%$ and $\mathrm{FPG} \geq 126 \mathrm{mg} / \mathrm{dL}$ at 1 week before randomization, fasting C-peptide concentration $\geq 1.0 \mathrm{ng} / \mathrm{mL}$ at screening, and body mass index $\leq 40 \mathrm{~kg} / \mathrm{m}^{2}$ at screening.

Key exclusion criteria were symptoms of poorly controlled T2DM, including but not limited to marked polyuria and polydipsia, with a $>10 \%$ weight loss in the 3 months prescreening or other signs or symptoms of poorly controlled hyperglycemia; history of diabetic ketoacidosis or hyperosmolar nonketotic coma; and insulin therapy within 1 year of screening, except for during a hospitalization or use in gestational diabetes. Patients were also excluded if they had a significant cardiovascular history, defined as a history of myocardial infarction, coronary angioplasty or bypass graft(s), valvular disease or repair, unstable angina pectoris, transient ischemic attack, or cerebrovascular accident $\leq 6$ months before study entry; or congestive heart failure, defined as New York Heart Association class III and IV and/or known left ventricular ejection fraction $\leq 40 \%$. Also excluded were patients with chronic or repeated intermittent corticosteroid treatment and a history of unstable or rapidly progressing renal disease; an unstable major psychiatric disorder; a history of hemoglobinopathies; donation of blood or plasma to a blood bank $\leq 3$ months prescreening; and active liver disease or infection or clinically significant abnormalities on screening tests of hepatic, renal, endocrine, metabolic, or hematologic function. Women who were pregnant or breastfeeding were excluded, and sexually active women of childbearing potential and fertile men whose partners were women of childbearing potential were required to use an acceptable method of contraception throughout the study.

After screening, eligible patients completed a single-blind, lead-in period, during which they received metformin XR 1,500 $\mathrm{mg}$ (Fig. 1). The lead-in period was 8 weeks for patients who were currently receiving metformin IR $\leq 1,500 \mathrm{mg}$ or metformin $\mathrm{XR}<1,500 \mathrm{mg}$ and 4 weeks for patients already receiving metformin XR 1,500 mg. After completing the lead-in period, patients with $\mathrm{HbA}_{1 \mathrm{c}} 7-11 \%$ and FPG $\geq 126 \mathrm{mg} / \mathrm{dL}$ and good adherence (80-120\%) with study medication were randomly assigned in a $1: 1$ ratio to treatment with double-blind saxagliptin $5 \mathrm{mg}$ added to open-label metformin XR 1,500 mg or doubleblind metformin XR $500 \mathrm{mg}$ added to openlabel metformin XR 1,500 mg (uptitrated metformin XR 2,000 mg). Randomization was accomplished using an interactive voiceresponse system and a blocked randomization schedule with block size of 2. All study medication was taken once daily with the evening meal.

Patients completed 24-h domicile visits at randomization and at the end of the 4-week treatment period for assessment of 24-h MWG. During each domicile visit, patients received standardized meals. The standardized evening meal consisted of two 8-ounce containers of Boost Plus ${ }^{\circledR}$ (Nestlé S.A., Vevey, Switzerland) and 1 Zone Perfect ${ }^{\circledR}$ bar (Abbott Laboratories, Columbus, OH, USA). The Boost Plus energy drinks provided 360 calories per 8-ounce container, with $14 \mathrm{~g}$ protein, $45 \mathrm{~g}$ carbohydrate, and $14 \mathrm{~g}$ fat; each Zone Perfect bar provided 200 calories, with $14 \mathrm{~g}$ protein, $25 \mathrm{~g}$ carbohydrate, and $6 \mathrm{~g}$ fat, for a meal total of 920 calories, with $42 \mathrm{~g}$ protein, $115 \mathrm{~g}$ carbohydrate, and $34 \mathrm{~g}$ fat. Breakfast and lunch were administered based on a sample 


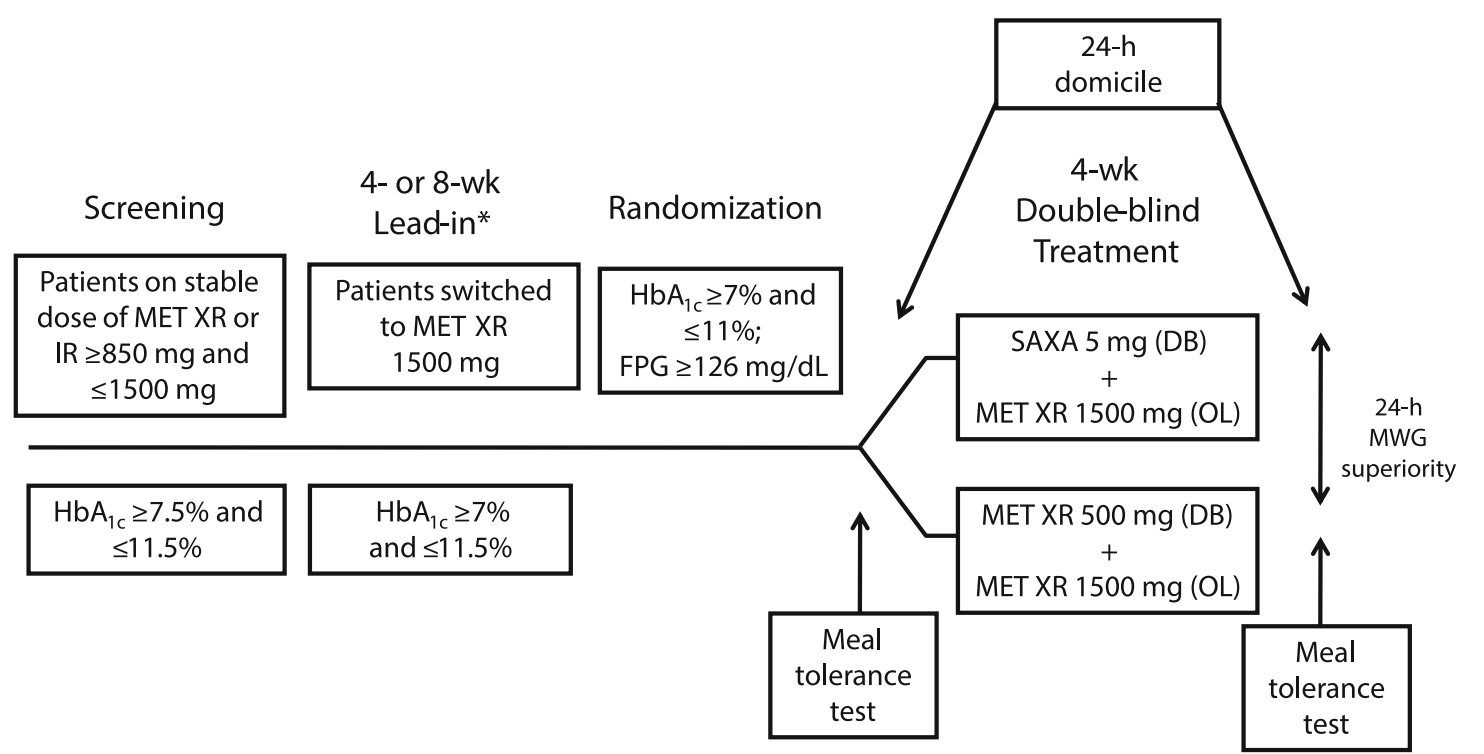

*4-wk lead-in for patients on MET XR $1500 \mathrm{mg}$ at screening; 8-wk lead-in for patients on MET XR $<1500 \mathrm{mg}$ or MET IR $\leq 1500 \mathrm{mg}$ at screening.

Fig. 1 Study design. $D B$ Double blind, $F P G$ fasting plasma glucose, $H b A_{1 c}$ glycated hemoglobin, $I R$ immediate release, $M E T X R$ metformin extended release, $M W G$ mean weighted glucose, $O L$ open label, $S A X A$ saxagliptin

menu created by a registered dietician and were to be followed exactly on both domicile days. The total caloric intake per $24 \mathrm{~h}$ during the domicile visit was 2,440 calories.

Blood for assessment of glucose level was drawn at 30 and 5 min before each meal and 30, $60,120,180$, and $240 \mathrm{~min}$ after each meal (240 min after the evening meal only), and at midnight, 3 a.m., and $24 \mathrm{~h}$ after the first blood draw.

All prior and current medications at screening and concomitant medications taken during the study were recorded. Patients using herbal or over-the-counter glucose-lowering agents were allowed to continue with the medications provided that doses remained stable throughout the study, but they could not begin treatment with these preparations during the study. Antihyperglycemic medications other than study medication were not permitted, with the exception of insulin during a hospitalization for other causes. Potent cytochrome P450 3A4 inducers and HIV antivirals were prohibited. Treatment with any systemic corticosteroid could not be started during the study.

\section{Efficacy Assessments}

The primary efficacy end point was the change from baseline to week 4 in 24-h MWG. The 24-h MWG was estimated by dividing the area under the 24-h glucose concentration curve by 24 .

The secondary efficacy end points were change from baseline to week 4 in 2-h PPG (2-h after the evening meal) and FPG (immediately before breakfast). The tertiary efficacy end point was the change in $\mathrm{HbA}_{1 \mathrm{c}}$ from baseline to week 4 . All glucose measurements for assessment of efficacy end points were processed at a central laboratory.

\section{Safety and Tolerability Assessments}

All adverse events, serious adverse events, and discontinuations due to adverse events were 
recorded. Safety and tolerability also were assessed by evaluating changes in 12-lead electrocardiograms (ECGs), vital signs, and clinical laboratory tests.

\section{Statistical Analysis}

A sample size of 36 patients per group was estimated to provide $90 \%$ power to detect a difference of $18 \mathrm{mg} / \mathrm{dL}$ in MWG from baseline to week 4 between the two treatment groups. Assuming approximately $20 \%$ of patients would discontinue without a valid efficacy assessment at week 4, 90 patients needed to be randomized.

The change from baseline to week 4 in 24-h MWG (primary efficacy end point) was analyzed in the randomized data set (all randomized patients who took $\geq 1$ dose of study medication) for patients who had a baseline measurement and a post-randomization measurement for the time point analyzed using analysis of covariance (ANCOVA), including treatment group, baseline value, and country in the model.

The change from baseline to week 4 in 2-h PPG (secondary efficacy end point) was analyzed using the same ANCOVA used for the primary efficacy end point. Change from baseline to week 4 in FPG (secondary efficacy end point) was analyzed using ANCOVA, with treatment group, baseline value, and country in the model, and using last-observation-carried-forward methods. The change from baseline to week 4 in $\mathrm{HbA}_{1 \mathrm{c}}$ (tertiary efficacy end point) was analyzed using ANCOVA, with treatment group, baseline values, and country in the model.

Statistical testing of the primary and secondary efficacy end points was conducted sequentially to control the type I error rate at the 0.05 level. Safety analyses are presented descriptively, using data from all patients who took $\geq 1$ dose of study medication.

\section{RESULTS}

This study was conducted at 23 sites (14 in the USA, 4 in Israel, 3 in Mexico, and 2 in Argentina) between August 2009 and May 2010. Of 126 patients entering the lead-in period; 93 patients were randomized and treated (Fig. 2). Ninety patients (96.8\%) completed the 4-week treatment period. One patient in each group discontinued because they withdrew consent, and 1 patient in the saxagliptin + metformin XR group died on day 9 from chronic ischemic heart disease with cardiomegaly. This death was not considered by the investigator to be related to study drug. Treatment groups were generally balanced with regard to demographic and baseline clinical characteristics (Table 1). Most patients were white, and there were similar proportions of men and women. The mean duration of diabetes was longer in the saxagliptin + metformin XR group, 6.2 years, than in the uptitrated metformin XR group, 5.1 years.

All patients had received metformin before study entry. One patient in the saxagliptin + metformin XR group had previously received pioglitazone + metformin and 1 patient in the uptitrated metformin XR group had received rosiglitazone + metformin. The proportion of patients receiving concomitant medications during the study was similar in each treatment group $(54.3 \%$ for saxagliptin + metformin XR and $53.2 \%$ for uptitrated metformin XR). The most commonly used concomitant medications in the saxagliptin + metformin $\mathrm{XR}$ and uptitrated metformin XR groups were cardiovascular system medications, primarily antihypertensives (32.6\% and 34.0\%, respectively), and nervous system medications, including antiepileptics, anxiolytics, antivertigo, and opioids (23.9\% and $36.2 \%$, respectively). 


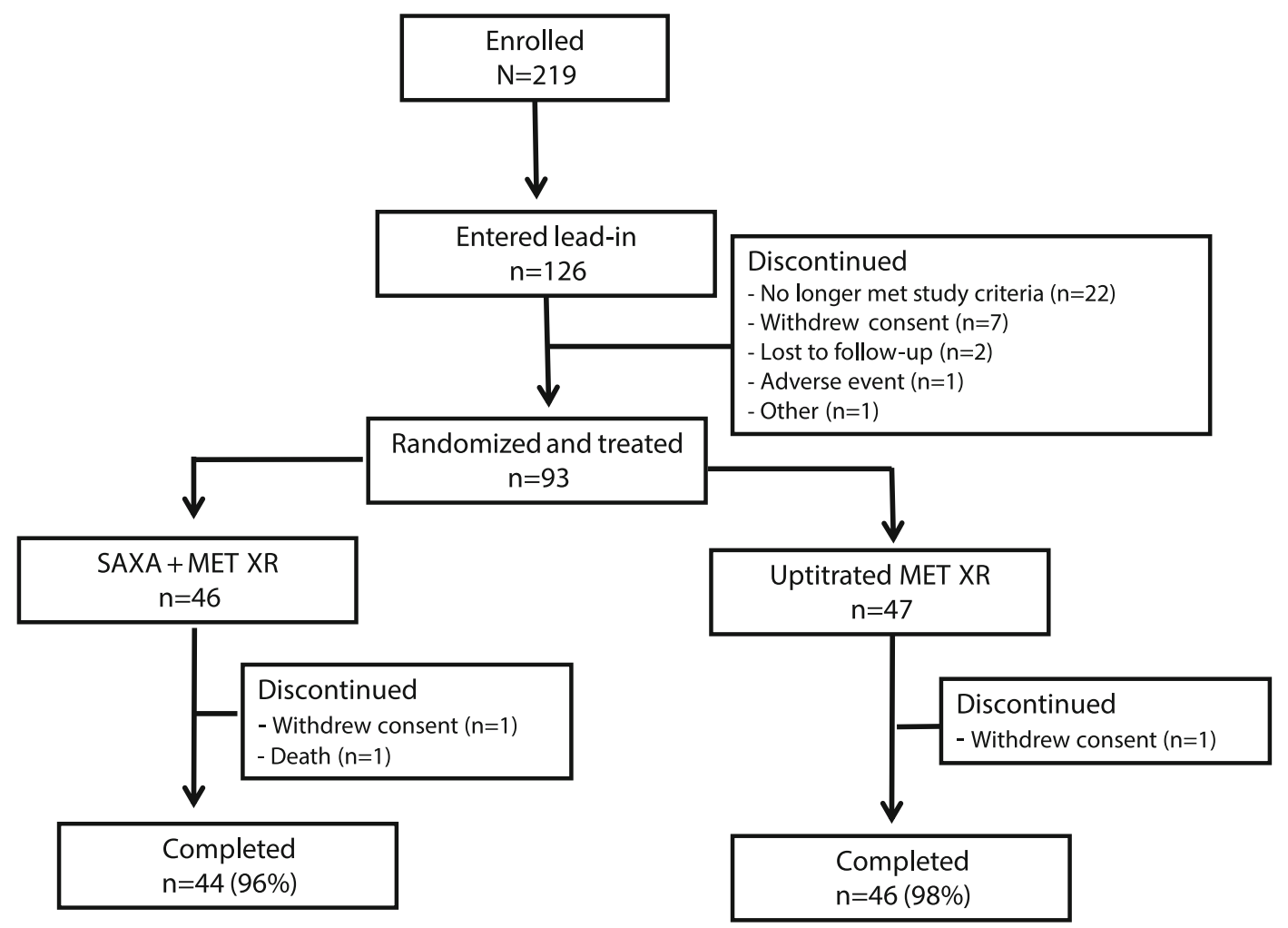

Fig. 2 Patient disposition. MET XR metformin extended release, $S A X A$ saxagliptin

\section{Efficacy}

At baseline, mean \pm SE 24-h MWG was $191.3 \pm 6.3 \mathrm{mg} / \mathrm{dL} \quad$ in the saxagliptin + metformin XR group and $192.0 \pm 6.1 \mathrm{mg} / \mathrm{dL}$ in the uptitrated metformin XR group. The adjusted mean \pm SE change from baseline to week 4 was $-19.0 \pm 5.7 \mathrm{mg} / \mathrm{dL}(95 \%$ CI -30.3 to -7.6$)$ for saxagliptin + metformin $\mathrm{XR}$ and $-8.2 \pm 6.0 \mathrm{mg} / \mathrm{dL}(95 \% \mathrm{CI}-20.0$ to -3.7$)$ for uptitrated metformin XR. The mean \pm SE between-group difference was $-10.8 \pm 7.01$ $\mathrm{mg} / \mathrm{dL}(95 \% \mathrm{CI}-24.8$ to $3.2 ; P=0.1278)$ for saxagliptin + metformin $\mathrm{XR}$ versus uptitrated metformin XR (Table 2). In keeping with the sequential statistical analysis procedure used in this study, because between-group differences in the primary end point did not reach statistical significance, the significance of differences in secondary and tertiary efficacy end points was not calculated.

The 24-h glucose profile was comparable between groups at baseline (Fig. 3a). At week 4, between-group differences were observed, with lower glucose levels recorded in patients receiving saxagliptin + metformin $\quad \mathrm{XR}$ compared with patients receiving uptitrated metformin XR (Fig. 3b). The mean change from baseline in 24-h glucose levels at week 4 was generally greater at all but one time point with saxagliptin + metformin $\mathrm{XR}$ than with uptitrated metformin XR (Fig. 3c).

At week 4 , the adjusted mean \pm SE change from baseline for 2-h PPG was greater with saxagliptin + metformin XR than with uptitrated metformin XR (Table 3); the mean $\pm \mathrm{SE}$ between-group difference was $-31.1 \pm 11.8 \mathrm{mg} / \mathrm{dL}(95 \% \mathrm{CI}-54.6$ to -7.7$)$. 
Table 1 Baseline demographic and clinical characteristics

\begin{tabular}{|c|c|c|}
\hline & $\begin{array}{l}\text { SAXA + MET } \\
\text { XR }(n=46)\end{array}$ & $\begin{array}{l}\text { Uptitrated } \\
\text { MET XR } \\
(n=47)\end{array}$ \\
\hline \multicolumn{3}{|l|}{ Sex, $n(\%)$} \\
\hline Men & $25(54.3)$ & $22(46.8)$ \\
\hline Women & $21(45.7)$ & $25(53.2)$ \\
\hline \multicolumn{3}{|l|}{ Age, years } \\
\hline Mean $\pm S D$ & $53.9 \pm 9.4$ & $50.6 \pm 9.7$ \\
\hline Range & $30-72$ & $29-68$ \\
\hline \multicolumn{3}{|l|}{ Age group, $n(\%)$} \\
\hline$<65$ years & $40(87.0)$ & $45(95.7)$ \\
\hline$\geq 65$ years & $6(13.0)$ & $2(4.3)$ \\
\hline \multicolumn{3}{|l|}{ Race, $n(\%)$} \\
\hline White & $43(93.5)$ & $45(95.7)$ \\
\hline Black & $3(6.5)$ & $2(4.3)$ \\
\hline \multicolumn{3}{|l|}{ Ethnicity, $n(\%)$} \\
\hline Hispanic/Latino & $16(34.8)$ & $17(36.2)$ \\
\hline Not Hispanic/Latino & $8(17.4)$ & $8(17.0)$ \\
\hline Not reported & $22(47.8)$ & $22(46.8)$ \\
\hline \multicolumn{3}{|l|}{ Geographic region, $n(\%)$} \\
\hline North America & $24(52.2)$ & $25(53.2)$ \\
\hline Latin America & $18(39.1)$ & $20(42.6)$ \\
\hline Europe & $4(8.7)$ & $2(4.3)$ \\
\hline Mean $\pm S D$ weight, $\mathrm{kg}$ & $91.3 \pm 18.4$ & $86.9 \pm 15.2$ \\
\hline Mean $\pm S D$ BMI, $\mathrm{kg} / \mathrm{m}^{2}$ & $32.5 \pm 5.1$ & $31.1 \pm 4.3$ \\
\hline $\begin{array}{l}\text { Mean } \pm \text { SD duration of } \\
\text { diabetes, years }\end{array}$ & $6.2 \pm 4.5$ & $5.1 \pm 3.9$ \\
\hline \multicolumn{3}{|l|}{$\mathrm{HbA}_{1 \mathrm{c}}, \%$} \\
\hline Mean \pm SD & $8.6 \pm 0.9$ & $8.4 \pm 0.9$ \\
\hline \multicolumn{3}{|l|}{ Categorized, $n(\%)$} \\
\hline$<8 \%$ & $11(23.9)$ & $16(34.0)$ \\
\hline$\geq 8-<9 \%$ & $20(43.5)$ & $20(42.6)$ \\
\hline$\geq 9 \%$ & $15(32.6)$ & $11(23.4)$ \\
\hline
\end{tabular}

Table 1 continued

\begin{tabular}{lll}
\hline & $\begin{array}{l}\text { SAXA + MET } \\
\text { XR }(n=46)\end{array}$ & $\begin{array}{l}\text { Uptitrated } \\
\text { MET XR } \\
(n=47)\end{array}$ \\
\hline $\begin{array}{l}\text { Mean } \pm \text { SD 2-h PPG, } \\
\mathrm{mg} / \mathrm{dL}\end{array}$ & $281.3 \pm 51.6$ & $283.3 \pm 66.1$ \\
$\begin{array}{l}\text { Mean } \pm \text { SD FPG, } \\
\mathrm{mg} / \mathrm{dL}\end{array}$ & $163.5 \pm 32.3$ & $164.2 \pm 36.2$ \\
\hline
\end{tabular}

BMI Body mass index, FPG fasting plasma glucose (immediately before breakfast), $H b A_{1 c}$ glycated hemoglobin, MET XR metformin extended release, $P P G$ postprandial glucose ( $2 \mathrm{~h}$ after the evening meal), $S A X A$ saxagliptin, $S D$ standard deviation

For FPG, the adjusted mean \pm SE change from baseline was also greater for saxagliptin + metformin XR than for uptitrated metformin $\mathrm{XR}$ (Table 3); the mean $\pm \mathrm{SE}$ between-group difference was $-5.7 \pm 7.2 \mathrm{mg} / \mathrm{dL} \quad(95 \% \quad$ CI -20.0 to 8.5 ). The adjusted mean \pm SE change from baseline for $\mathrm{HbA}_{1 \mathrm{c}}$ was slightly greater for saxagliptin + metformin XR than for uptitrated metformin XR (Table 3); the mean $\pm \mathrm{SE}$ between-group difference was $-0.1 \pm 0.1 \%$ (95\% CI -0.3 to 0.0 ).

During the screening period, the mean $\mathrm{HbA}_{1 \mathrm{c}}$ decreased in patients that were to be subsequently randomized to the two groups at week -4 , after all of these patients were switched to metformin XR 1,500 mg (Fig. 4). However, mean $\mathrm{HbA}_{1 \mathrm{c}}$ continued to decline from week -4 to week 0 (pre-randomization) in the uptitrated metformin XR group but remained stable in the saxagliptin + metformin XR group. Mean $\mathrm{HbA}_{1 \mathrm{c}}$ continued to decrease in both groups during the doubleblind treatment period and was similar in both groups at week 4, despite a higher mean $\mathrm{HbA}_{1 \mathrm{c}}$ at randomization in the saxagliptin + metformin group. 
Table 2 Adjusted mean change from baseline to week 4 in 24-h MWG

\begin{tabular}{lll}
\hline & $\begin{array}{l}\text { SAXA + MET XR } \\
(n=46)\end{array}$ & \multicolumn{1}{c}{$\begin{array}{c}\text { Uptitrated MET XR } \\
(\boldsymbol{n}=47)\end{array}$} \\
\hline$N$ & 43 & 44 \\
Baseline mean $\pm \mathrm{SE}, \mathrm{mg} / \mathrm{dL}$ & $191.3 \pm 6.3$ & $192.0 \pm 6.1$ \\
Adjusted mean $\pm \mathrm{SE}$ change from baseline, $\mathrm{mg} / \mathrm{dL}$ & $-19.0 \pm 5.7$ & $-8.2 \pm 6.0$ \\
$95 \% \mathrm{CI}$ & -30.3 to -7.6 & 3.7 \\
Mean \pm SE difference vs uptitrated MET XR, $\mathrm{mg} / \mathrm{dL}$ & $-10.8 \pm 7.01$ & -24.8 to 3.2 \\
$95 \% \mathrm{CI}$ for difference & 0.1278 & \\
$P$ value for difference & & \\
\hline
\end{tabular}

CI Confidence interval, MET XR metformin extended release, $M W G$ mean weighted glucose, $S A X A$ saxagliptin, $S E$ standard error

\section{Safety and Tolerability}

Adverse events of any causality, were reported by $8(17.4 \%)$ patients in the saxagliptin + metformin XR group, compared with 15 (31.9\%) in the uptitrated metformin XR group (Table 4). No serious adverse events occurred in either treatment group. The single death that occurred during the study was related to chronic ischemic heart disease in a patient in the saxagliptin + metformin XR group and was not considered related to study drug. No patient in either treatment group discontinued the current study because of an adverse event. Cough was the only adverse event that occurred in $\geq 5 \%$ of patients in either treatment group $(n=3$ [6.5\%] in the saxagliptin + metformin XR group and $n=0$ [0\%] of the uptitrated metformin XR group). Although the incidence of gastrointestinal adverse events is reported to be lower with metformin XR than with metformin IR [21], the proportion of patients experiencing any gastrointestinal adverse event was higher with uptitrated metformin XR $(n=5$ [10.6\%]) than with saxagliptin + metformin $\quad \mathrm{XR} \quad(n=1$
[2.2\%]). Excluding hypoglycemia, treatmentrelated adverse events occurred in only 1 patient, who was in the uptitrated metformin XR group. This patient had 3 gastrointestinal adverse events (upper abdominal pain, diarrhea, and nausea).

There were no reported adverse events of lymphopenia, thrombocytopenia, localized edema, hypersensitivity, pancreatitis, jaundice, or skin-related adverse events during the doubleblind treatment period. Few infections were reported in either treatment group $(n=2$, [4.3\%] in each group). There were no reports of confirmed hypoglycemia (defined as a fingerstick glucose value $\leq 50 \mathrm{mg} / \mathrm{dL}$ in the presence of symptoms) in any patient from either group. Reported hypoglycemia was recorded for 1 patient $(2.2 \%)$ in the saxagliptin + metformin XR group and in 2 patients (4.3\%) in the uptitrated metformin XR group.

No electrocardiogram (ECG) abnormalities, clinically meaningful changes in blood pressure, or clinically relevant changes in laboratory test results, including those for liver function, were reported in either treatment group. 


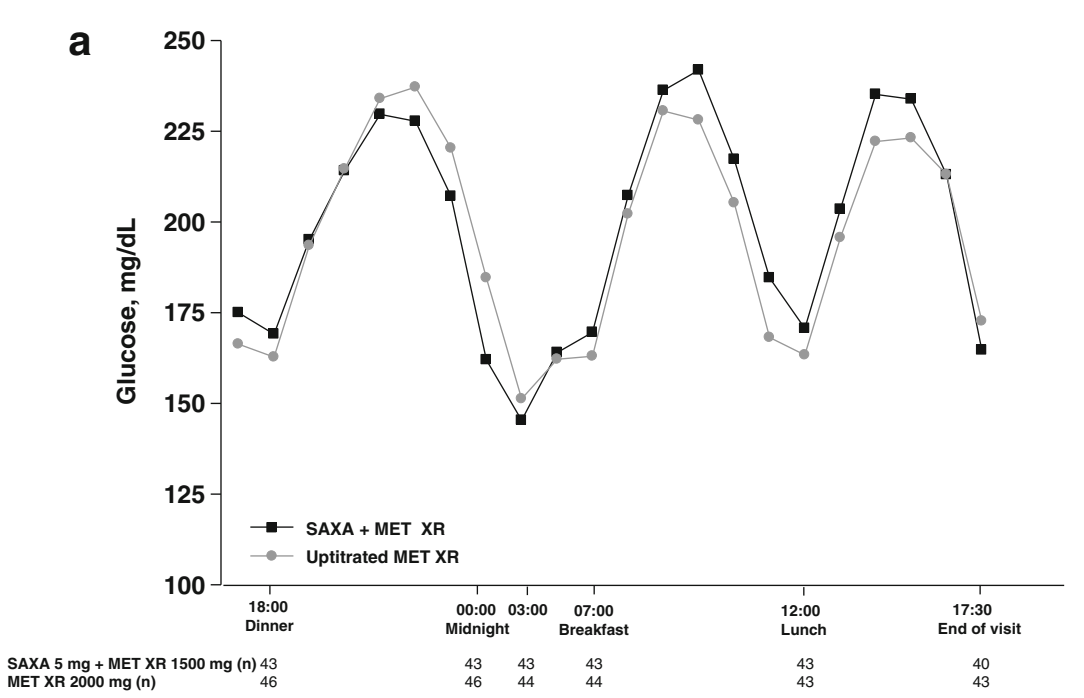

SAXA $5 \mathrm{mg}+$ MET XR $1500 \mathrm{mg}$ (n) 43
MET XR $2000 \mathrm{mg}(\mathrm{n})$

$\begin{array}{lll}43 & 43 & 43 \\ 46 & 44 & 44\end{array}$

b

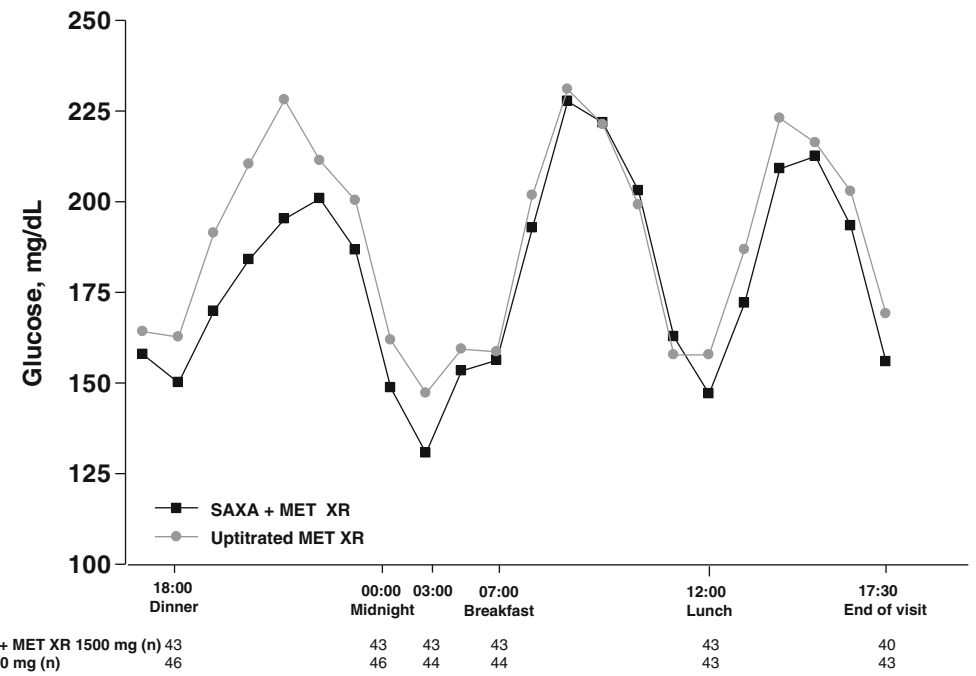

SAXA $5 \mathrm{mg}+$ MET XR $1500 \mathrm{mg}$ (n) 43
MET XR $2000 \mathrm{mg}$ (n)

$\begin{array}{lll}43 & 43 & 43 \\ 46 & 44 & 44\end{array}$

40

C

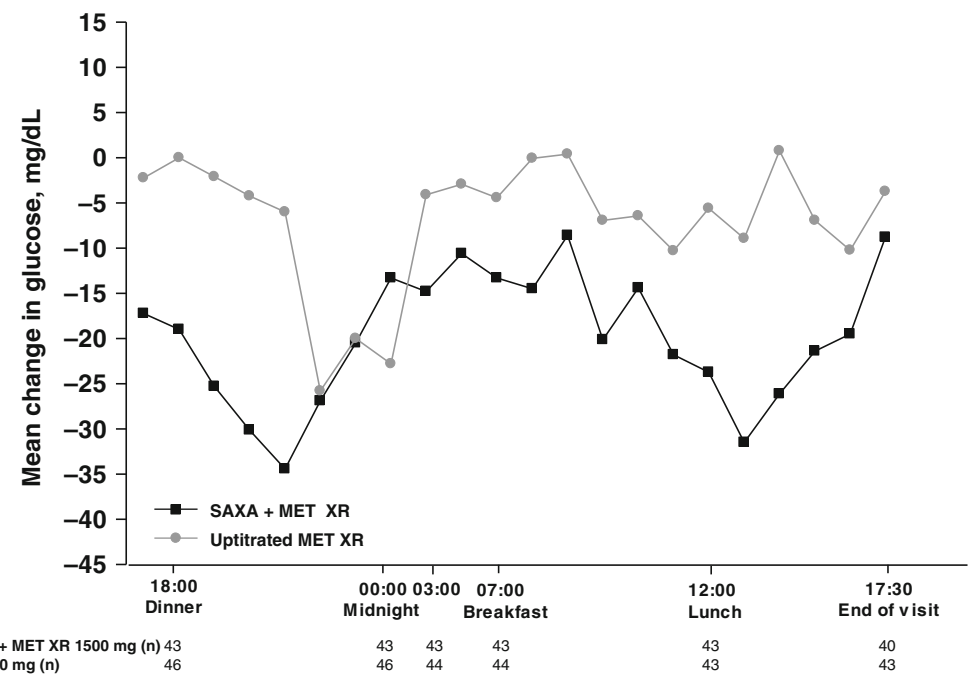


4 Fig. 3 The 24-h glucose profile at a baseline and b week 4 and mean change from baseline at c week 4 in 24-h glucose profile for patients receiving SAXA + MET XR and for patients receiving uptitrated MET XR. MET XR Metformin extended release, $S A X A$ saxagliptin

\section{DISCUSSION}

This 4-week study was carried out to compare the impact of adding saxagliptin $5 \mathrm{mg}$ to metformin XR 1,500 mg versus uptitration of metformin XR to 2,000 $\mathrm{mg}$ on measures of daily glucose control, including 24-h MWG, 2-h PPG, and FPG in patients with T2DM whose glucose levels were not adequately controlled with metformin monotherapy. Although $\mathrm{HbA}_{1 \mathrm{c}}$ is an important parameter for examining glycemic control over time, it provides limited benefit in understanding the daily fluctuations experienced by patients. This study evaluated the impact of 2 commonly used paradigms of

Table 3 Change in secondary efficacy variables from baseline to week 4

\begin{tabular}{|c|c|c|}
\hline & SAXA + MET XR $(n=46)$ & Uptitrated MET XR $(n=47)$ \\
\hline \multicolumn{3}{|l|}{ 2-h PPG, mg/dL } \\
\hline$N$ & 44 & 46 \\
\hline Baseline mean \pm SE & $229.7 \pm 9.1$ & $234.0 \pm 10.3$ \\
\hline Adjusted mean $\pm S E$ change from baseline & $-31.4 \pm 9.7$ & $-0.2 \pm 10.1$ \\
\hline $95 \% \mathrm{CI}$ & -50.6 to -12.1 & -20.3 to 19.8 \\
\hline Mean \pm SE difference vs uptitrated MET XR & $-31.1 \pm 11.8$ & \\
\hline 95\% CI for difference & -54.6 to -7.7 & \\
\hline \multicolumn{3}{|l|}{$\mathrm{FPG}, \mathrm{mg} / \mathrm{dL}$} \\
\hline$n$ & 45 & 47 \\
\hline Baseline mean $\pm \mathrm{SE}$ & $162.9 \pm 4.8$ & $164.2 \pm 5.3$ \\
\hline Adjusted mean $\pm S E$ change from baseline & $-9.3 \pm 5.9$ & $-3.6 \pm 6.2$ \\
\hline $95 \% \mathrm{CI}$ & -21.1 to 2.5 & -15.8 to 8.7 \\
\hline Mean \pm SE difference vs uptitrated MET XR & $-5.7 \pm 7.2$ & \\
\hline 95\% CI for difference & -20.0 to 8.5 & \\
\hline \multicolumn{3}{|l|}{$\mathrm{HbA}_{1 \mathrm{c}}, \%$} \\
\hline$n$ & 43 & 43 \\
\hline Baseline mean $\pm S E$ & $8.6 \pm 0.13$ & $8.3 \pm 0.12$ \\
\hline Adjusted mean \pm SE change from baseline & $-0.4 \pm 0.1$ & $-0.2 \pm 0.1$ \\
\hline $95 \% \mathrm{CI}$ & -0.5 to -0.2 & -0.4 to -0.1 \\
\hline Mean \pm SE difference vs uptitrated MET XR & $-0.1 \pm 0.1$ & \\
\hline $95 \%$ CI for difference & -0.3 to 0.0 & \\
\hline
\end{tabular}

CI Confidence interval, FPG fasting plasma glucose (immediately before breakfast), $H b A_{1 c}$ glycated hemoglobin, $M E T X R$ metformin extended release, $P P G$ postprandial glucose ( $2 \mathrm{~h}$ after the evening meal), $S A X A$ saxagliptin, $S E$ standard error 


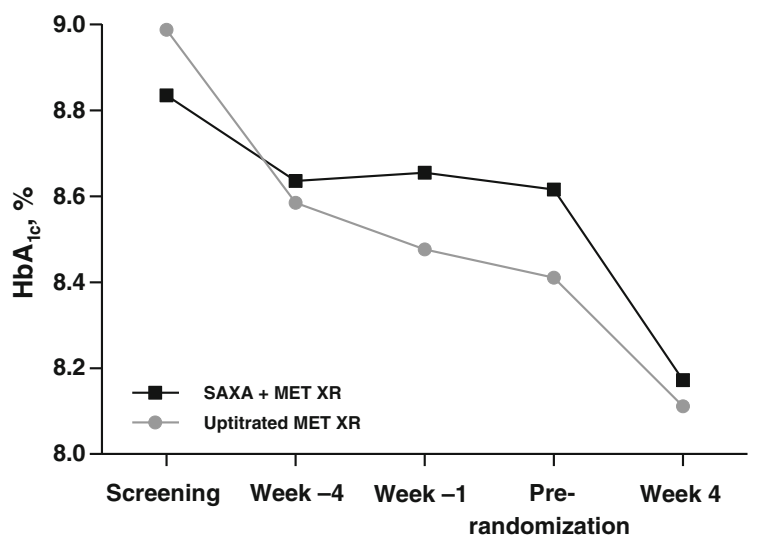

Fig. 4 Mean glycated hemoglobin $\left(\mathrm{HbA}_{1 \mathrm{c}}\right)$ from screening to week 4. MET XR Metformin extended release, $S A X A$ saxagliptin

diabetes treatment in patients inadequately controlled with metformin: addition of drugs with complementary mechanisms of action and uptitration of existing therapy. The results indicate that short-term treatment with saxagliptin $5 \mathrm{mg}$ added to metformin $\mathrm{XR}$ $1,500 \mathrm{mg}$ once daily is generally well tolerated and may provide greater improvements in glycemic control compared with uptitrating metformin XR from 1,500 to 2,000 mg. The decreases in mean plasma glucose levels with the addition of saxagliptin were most noteworthy after meals, consistent with the incretin-mediated mechanism of action of saxagliptin.

The observation that the difference between saxagliptin + metformin XR and uptitrated metformin XR groups in the primary efficacy end point did not reach statistical significance may reflect the higher-than-expected variability in 24-h MWG data within each treatment group. In turn, it is possible that this variability may result from inequalities between the treatment groups at baseline. As shown in Fig. 4, patients who were later assigned to the saxagliptin group appeared to have a stable $\mathrm{HbA}_{1 \mathrm{c}}$ during the lead-in period,
Table 4 Summary of adverse events

\begin{tabular}{|c|c|c|}
\hline & \multicolumn{2}{|l|}{ Patients, $n(\%)$} \\
\hline & $\begin{array}{l}\text { SAXA + MET } \\
\text { XR }(n=46)\end{array}$ & $\begin{array}{l}\text { Uptitrated } \\
\text { MET XR } \\
(n=47)\end{array}$ \\
\hline \multicolumn{3}{|l|}{ Adverse events } \\
\hline Any & $8(17.4 \%)$ & $15(31.9 \%)$ \\
\hline Treatment related & 0 & $2(4.3 \%)$ \\
\hline \multicolumn{3}{|l|}{ Serious adverse events } \\
\hline Any nonfatal & 0 & 0 \\
\hline Treatment related & 0 & 0 \\
\hline \multicolumn{3}{|c|}{$\begin{array}{l}\text { Adverse events leading to } \\
\text { discontinuation }\end{array}$} \\
\hline Any & 0 & 0 \\
\hline Serious adverse event & 0 & 0 \\
\hline Deaths & $1^{\mathrm{a}}$ & 0 \\
\hline
\end{tabular}

MET XR Metformin extended release, SAXA saxagliptin

${ }^{a}$ Cause of death was chronic ischemic heart disease with cardiomegaly and was not considered related to study medication

whereas those later assigned to the metformin XR uptitration group appeared to have a continuing decline in $\mathrm{HbA}_{1 \mathrm{c}}$ before randomization, suggesting their glycemic status had not reached equilibrium. Thus, it is possible that the lead-in period may not have been sufficient to create a stable baseline. The number of patients who had their metformin XR dose uptitrated during the lead-in period was balanced between the two groups. In a 4-week, placebo-controlled trial of similar design that enrolled patients with demographic and clinical characteristics similar to those in our study, saxagliptin + metformin $\quad \mathrm{XR} \quad$ produced significantly greater decreases in 24-h MWG, compared with placebo (adjusted mean $\pm \mathrm{SE}$ change from baseline to week $4,-13.8 \pm 3.0$ vs $3.0 \pm 3.0 \mathrm{mg} / \mathrm{dL} ; 95 \% \mathrm{CI}$ for difference, -25.1 to 
$-8.5 ; P=0.0001$ ) [22]. Differences in other glycemic measures, including 2-h PPG, mean daily glucose, and 2-day average FPG, were also significantly greater with saxagliptin + metformin XR, compared with placebo. In contrast with the current study, the patients in that study did not change their metformin dose during the lead-in period [22].

The interpretation of the $\mathrm{HbA}_{1 \mathrm{c}}$ results is limited by the short duration of the current study. $\mathrm{HbA}_{1 \mathrm{c}}$ is a more stable end point than MWG, and with a longer duration of treatment, differences in effect on $\mathrm{HbA}_{1 \mathrm{c}}$ between saxagliptin + metformin $\mathrm{XR}$ and uptitrated metformin XR would be expected to be demonstrated, as reported in a similarly designed 18-week study [12]. In that study, the decrease in $\mathrm{HbA}_{1 \mathrm{c}}$ at week 18 was significantly greater with saxagliptin + metformin XR, compared with uptitrated metformin $\mathrm{XR}$ (adjusted mean change from baseline, $-0.88 \%$ vs $-0.35 \%$; $95 \%$ CI for difference, -0.73 to $-0.31 ; P<0.0001)$. In this longer trial, 24-h MWG was not an end point [12]. Given that the design of that study was almost identical to the design of the current study, it is likely that addon therapy with saxagliptin versus uptitration of metformin would have resulted in significant decreases in $\mathrm{HbA}_{1 \mathrm{c}}$ if the current study had extended beyond 4 weeks.

Along with considerations of efficacy, tolerability, and safety, it is also important to include cost-effectiveness as a factor in the decision to add saxagliptin to metformin XR therapy. To the authors knowledge, the costeffectiveness of saxagliptin + metformin XR, compared with uptitrated metformin $\mathrm{XR}$ has yet to be assessed. However, recent studies performed in Germany and Sweden have reported saxagliptin plus metformin to be cost-effective compared with metformin plus sulfonylurea, based on relatively greater improvements in quality-adjusted life years $[23,24]$.

The current study is limited in that it presents the outcomes achieved in a small number of patients, examining a nonstandard, mechanistic end point after only 4 weeks of treatment. Therefore, these results may not be applicable to patients receiving longer-term treatment.

\section{CONCLUSION}

Short-term treatment with saxagliptin $5 \mathrm{mg}$ added to metformin XR 1,500 mg once daily was generally well tolerated in patients with T2DM who had inadequate glycemic control with metformin monotherapy. Saxagliptin + metformin XR produced numerically greater, although not statistically significant, decreases in 24-h MWG, 2-h PPG, and FPG with fewer gastrointestinal adverse events, compared with uptitrating metformin XR from 1,500 to 2,000 mg.

\section{ACKNOWLEDGMENTS}

Sponsorship and article processing charges for this study was funded by Bristol-Myers Squibb and AstraZeneca LP. Medical writing support for the preparation of this manuscript was provided by Judy Fallon, PharmD, and Karen Zimmermann (Complete Healthcare Communications, Inc., Chadds Ford, PA), with funding from Bristol-Myers Squibb and AstraZeneca.

Dr. Karyekar is the guarantor for this article, and takes responsibility for the integrity of the work as a whole.

Conflict of interest. Joel Neutel has served as an advisor or consultant for Daiichi Sankyo, 
Inc., Forest Laboratories, Inc., and Merck \& Co., Inc, and served as a speaker or a member of a speakers' bureau for Boehringer Ingelheim Pharmaceuticals, Inc. and Daiichi Sankyo, Inc. Cathy Zhao is an employee of Bristol-Myers Squibb and owns Bristol-Myers Squibb shares. Chetan Karyekar is an employee of BristolMyers Squibb and owns Bristol-Myers Squibb shares.

Compliance with ethics guidelines. The study protocol for this international, randomized, double-blind, phase $3 \mathrm{~b}$ trial was approved by the institutional review board and independent ethics committee at each site, and the study was conducted in accordance with Good Clinical Practice, as defined by the International Conference on Harmonisation. All procedures followed were in accordance with the ethical standards of the responsible committee on human experimentation (institutional and national) and with the Helsinki Declaration of 1975, as revised in 2000. Informed consent was obtained from all patients before being included in the study.

Open Access. This article is distributed under the terms of the Creative Commons Attribution Noncommercial License which permits any noncommercial use, distribution, and reproduction in any medium, provided the original author(s) and the source are credited.

\section{REFERENCES}

1. Inzucchi SE, Bergenstal RM, Buse JB, et al. Management of hyperglycemia in type 2 diabetes: a patient-centered approach: position statement of the American Diabetes Association (ADA) and the European Association for the Study of Diabetes (EASD). Diabetes Care. 2012;35:1364-79.

2. Rodbard HW, Jellinger PS, Davidson JA, et al. Statement by an American Association of Clinical
Endocrinologists/American College of Endocrinology consensus panel on type 2 diabetes mellitus: an algorithm for glycemic control. Endocr Pract. 2009;15:540-59.

3. Monnier L, Mas E, Ginet C, et al. Activation of oxidative stress by acute glucose fluctuations compared with sustained chronic hyperglycemia in patients with type 2 diabetes. JAMA. 2006;295:1681-7.

4. Nathan DM, Kuenen J, Borg R, Zheng H, Schoenfeld D, Heine RJ. Translating the A1C assay into estimated average glucose values. Diabetes Care. 2008;31:1473-8.

5. Brick JC, Derr RL, Saudek CD. A randomized comparison of the terms estimated average glucose versus hemoglobin A1C. Diabetes Educ. 2009;35:596-602.

6. Bode BW. Defining the importance of daily glycemic control and implications for type 2 diabetes management. Postgrad Med. 2009;121:82-93.

7. Brown JB, Nichols GA, Perry A. The burden of treatment failure in type 2 diabetes. Diabetes Care. 2004;27:1535-40.

8. Nichols GA, Glauber HS, Javor K, Brown JB. Achieving further glycemic control in type 2 diabetes mellitus. West J Med. 2000;173:175-9.

9. Glucophage (metformin hydrochloride) and Glucophage XR (metformine hydrochloride extended-release). Full Prescribing Information. Princeton, NJ: Bristol-Myers Squibb Company; 2009.

10. Levy J, Cobas RA, Gomes MB. Assessment of efficacy and tolerability of once-daily extended release metformin in patients with type 2 diabetes mellitus. Diabetol Metab Syndr. 2010;2:16.

11. Turner RC, Cull CA, Frighi V, Holman RR. Glycemic control with diet, sulfonylurea, metformin, or insulin in patients with type 2 diabetes mellitus: progressive requirement for multiple therapies (UKPDS 49). UK Prospective Diabetes Study (UKPDS) Group. JAMA. 1999;281:2005-12.

12. Fonseca V, Zhu T, Karyekar C, Hirshberg B. Adding saxagliptin to extended-release metformin vs. uptitrating metformin dosage. Diabetes Obes Metab. 2012;14:365-71.

13. Weissman P, Goldstein BJ, Rosenstock J, et al. Effects of rosiglitazone added to submaximal doses of metformin compared with dose escalation of metformin in type 2 diabetes: the EMPIRE Study. Curr Med Res Opin. 2005;21:2029-35. 
14. Neumiller JJ, Campbell RK. Saxagliptin: a dipeptidyl peptidase- 4 inhibitor for the treatment of type 2 diabetes mellitus. Am J Health Syst Pharm. 2010;67:1515-25.

15. Holst JJ, Gromada J. Role of incretin hormones in the regulation of insulin secretion in diabetic and nondiabetic humans. Am J Physiol Endocrinol Metab. 2004;287:E199-206.

16. Drucker DJ. Enhancing incretin action for the treatment of type 2 diabetes. Diabetes Care. 2003;26:2929-40.

17. Ali S, Fonseca V. Saxagliptin overview: special focus on safety and adverse effects. Expert Opin Drug Saf. 2013;12:103-9.

18. Onglyza ${ }^{\circledR} \quad$ (saxagliptin). Full prescribing information. Princeton, NJ: Bristol-Myers Squibb Company; 2011.

19. Derosa G, Maffioli P. Patient considerations and clinical utility of a fixed dose combination of saxagliptin/metformin in the treatment of type 2 diabetes. Diabetes Metab Syndr Obes. 2011;4: 263-71.
20. Derosa G, Maffioli P. Dipeptidyl peptidase-4 inhibitors: 3 years of experience. Diabetes Technol Ther. 2012;14:350-64.

21. Davidson J, Howlett $H$. New prolonged-release metformin improves gastrointestinal tolerability. Br J Diabetes Vasc Dis. 2004;4:273-7.

22. Stenlof K, Raz I, Neutel J, Ravichandran S, Berglind $\mathrm{N}$, Chen R. Saxagliptin and metformin XR combination therapy provides glycemic control over 24 hours in patients with T2DM inadequately controlled with metformin. Curr Med Res Opin. 2010;26:2355-63.

23. Erhardt W, Bergenheim K, Duprat-Lomon I, McEwan P. Cost effectiveness of saxagliptin and metformin versus sulfonylurea and metformin in the treatment of type 2 diabetes mellitus in Germany: a Cardiff diabetes model analysis. Clin Drug Investig. 2012;32:189-202.

24. Granstrom O, Bergenheim K, McEwan P, Sennfalt $\mathrm{K}$, Henriksson M. Cost-effectiveness of saxagliptin $\left(\right.$ Onglyza $\left.{ }^{\circledR}\right)$ in type 2 diabetes in Sweden. Prim Care Diabetes. 2012;6:127-36. 